\title{
MRI diagnosis of Alexander disease
}

\author{
C G Muralidharan, MB BS, MD, Dip NB (Radiodiagnosis) \\ R P S Tomar, MB BS, MD (Paediatrics) \\ M H Jalandhar Hospital, Jalandhar, Punjab, India
}

\section{R Aggarwal, MB BS, MD (Radiodiagnosis)}

A F Hospital, Halwara, Punjab

Corresponding author: C Muralidharan (murali.cg@rediffmail.com)

\begin{abstract}
Alexander disease (fibrinoid leucodystrophy; originally described by Alexander in 1949) is a rare, fatal, nonfamilial leucoencephalopathy caused by astrocyte dysfunction characterised by missense mutation in the genes coding for glial fibrillary acidic protein (GFAP). It typically presents with frontal preponderance of white matter abnormalities and macroencephaly. We report a case of leucoencephalopathy with macroencephaly that shows characteristic MRI features of Alexander disease.
\end{abstract}

\section{S Afr J Rad 2012;16(3):116-117. DOI:10.7196/SAJR.656}

A 10-month-old term boy, firstborn of a non-consanguinous relationship, presented with a history of prolonged crying and seizures. No significant antenatal history was given, and the child had attained normal milestones until the age of 5 months, after which his development deteriorated. On examination, the head size was $55 \mathrm{~cm}$ (more than the 97th percentile for age of the patient). There were no signs or symptoms of raised intracranial tension such as vomiting, papilloedema etc. There was no normal eye contact, and global spasticity was noted.

Multiplanar imaging was done using T1 FLAIR, T2 FLAIR, and T2W FSE sequences, and post-contrast sequences on a $1.5 \mathrm{~T}$ highdefinition magnetic resonance (HDMR) imaging system (GE Signa
Excite 1.5T HD, USA). The MR study revealed bilaterally symmetrical confluent white matter hyperintensities on $\mathrm{T} 2 \mathrm{~W}$ images with frontal preponderance and involvement of the bilateral temporal and parietal lobes (Fig. 1). The subcortical U fibres were involved. Symmetrical bilateral hyperintensities on $\mathrm{T} 2 \mathrm{~W}$ images were also seen in external capsule, internal capsule, fornix, extreme capsule, corpus callosum and head of caudate nucleus. White matter expansion with resultant widened gyri was noted in the affected regions. All these regions were hypo-intense on T1W and T2 FLAIR. A periventricular rim, T2 hyper, T1 hypointense, was seen along the lateral ventricles (Figs 2a and $2 \mathrm{~b}$ ). The frontal lobes showed symmetrical areas of cavitation in the periventricular region (Fig. 3). Patchy symmetrical enhancement was noted in the periventricular rim and deep white matter of the frontal lobes (Figs $4 \mathrm{a}$ and $4 \mathrm{~b}$ ). MR spectroscopy did not reveal raised $\mathrm{N}$-acetylaspartate (NAA) or myoinositol peak. Based on these MR findings, a diagnosis of Alexander disease was made.

\section{Discussion}

Alexander disease (fibrinoid leucodystrophy), originally described by Alexander in $1949,{ }^{1}$ is a rare, fatal, nonfamilial leucoencephalopathy caused by astrocyte dysfunction characterised by missense mutation in the genes coding for glial fibrillary acidic protein(GFAP). ${ }^{2}$ The disease is classified into 3 types:

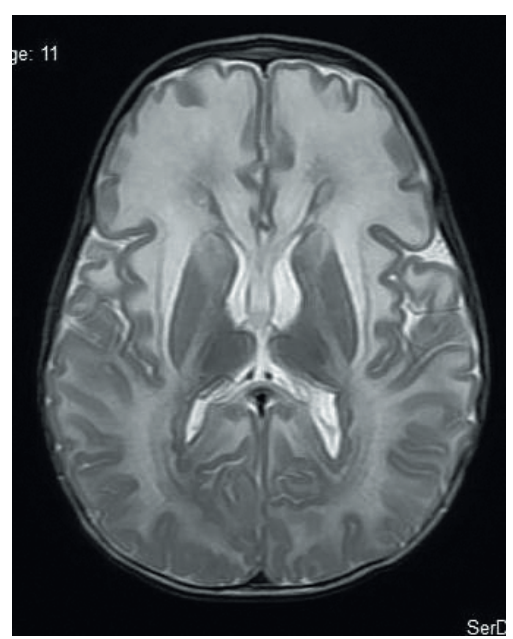

Fig. 1. T2W image shows bilaterally symmetrical white matter hyperintensities with frontal predominance and involvement of heads of the caudate nuclei.

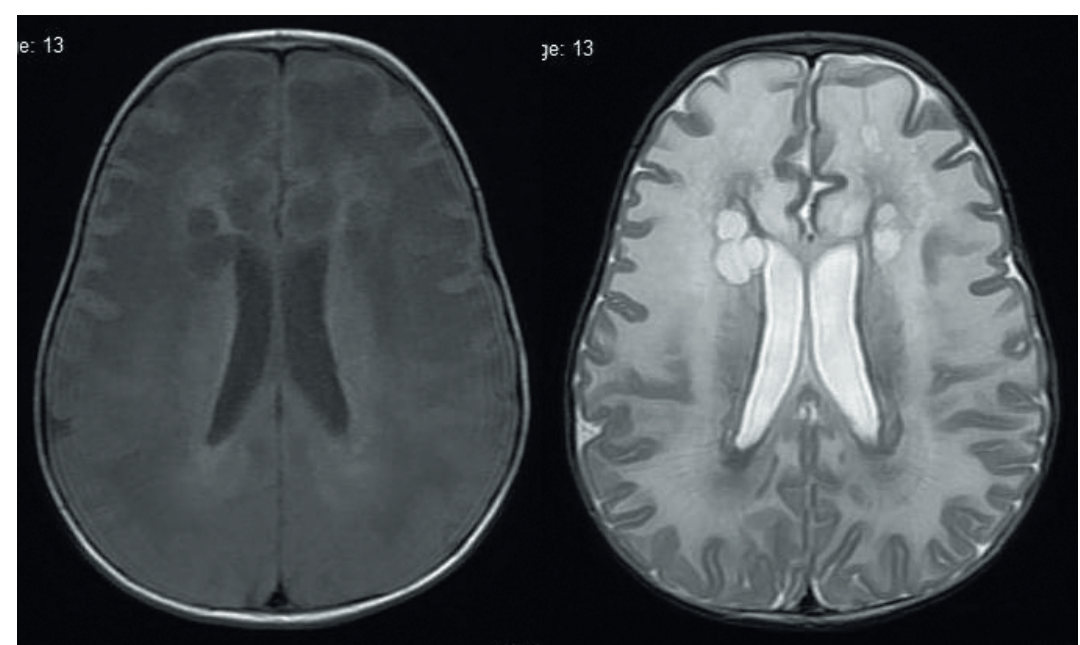

Fig. 2. T1W image (left) and T2W image (right) show a periventricular rim, hyperintense on $T 1 W$ and hypointense on $\mathrm{T} 2 \mathrm{~W}$, with cystic cavitation in the frontal periventricular region. 


\section{PICTORIAL INTERLUDE}

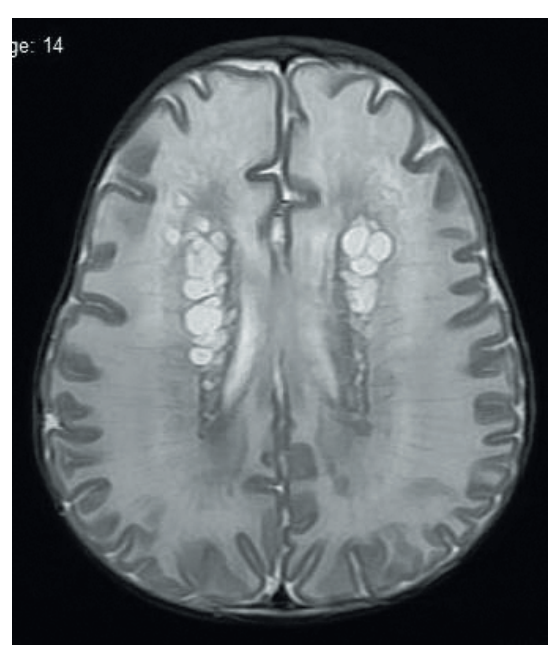

Fig. 3. T2W image shows bilaterally symmetrical cystic cavitation in the deep frontal and periventricular white matter.

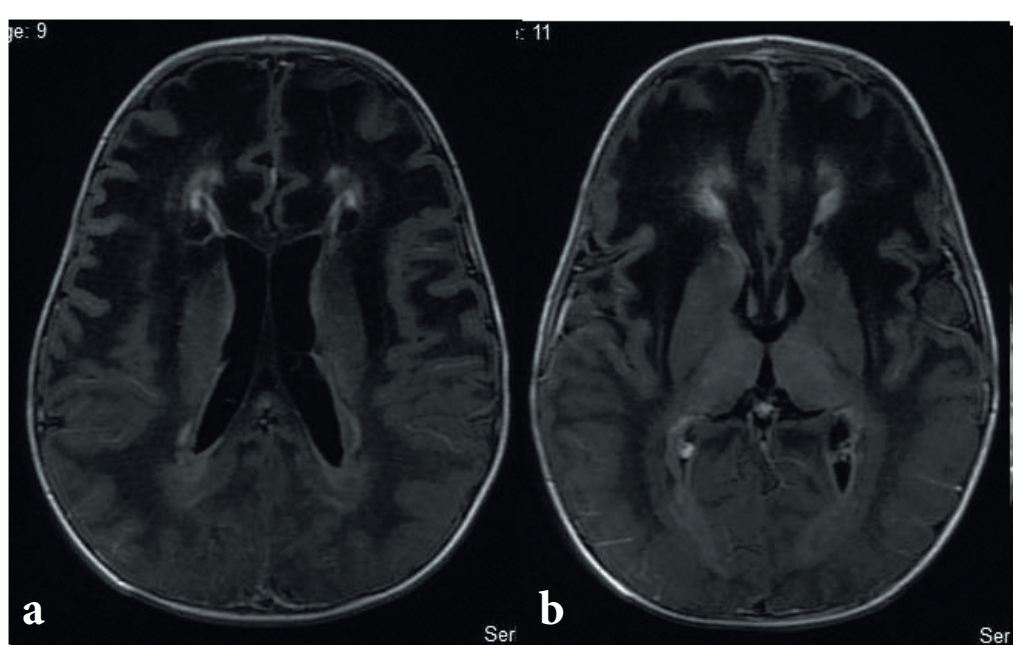

Fig. 4. Post-contrast T1W images show symmetrical enhancement of the periventricular rim, deep frontal white matter and heads of the caudate nuclei.
- cerebral Alexanders (type 1), which primarily has an infantile onset with the presence of seizures, psychomotor developmental retardation, macrocephaly and abnormalities in the superior frontal cerebral white matter observed in a brain MRI

- bulbospinal Alexanders (type 2), which primarily has an adult onset with the presence of muscle weakness, hyperreflexia, bulbar or pseudobulbar symptoms, signal abnormalities and atrophy observed in an MRI of the medulla oblongata and upper cervical spinal cord

- intermediate form (type 3) which has the characteristics of both the preceding. ${ }^{3}$

The MR imaging patterns of Alexander disease have been described to be quite specific, dissimilar from patients observed in other white matter abnormalities either of known ${ }^{4}$ or unknown origin. Five criteria were described by van der Knaap et al; ${ }^{4}$ our patient met 4 of them, with the additional finding of rarely described periventricular cavitation/cysts. ${ }^{6}$ Various differential diagnoses that were considered included Canavan disease, which is characterised by a combination of macroencephaly, extensive cerebral white matter changes (without frontal preponderance) and basal ganglia abnormalities. ${ }^{5}$ However, contrast enhancement does not occur in Canavan disease, and the typical raised $\mathrm{N}$-acetyl aspartate (NAA) peak on MR spectroscopy was absent in our patient.

Traditionally, biopsy was necessary to diagnose the disease, but diagnosis can now be made by MR imaging, using the criteria defined by van der Knaap et al. ${ }^{4}$ Additional confirmation can be obtained via genetic testing of a blood sample for missense mutation in the gene encoding for GFAP.

1. Alexander WS. Progressive fibrinoid degeneration of fibrillary astrocytes associated with mental retardation in a hydrocephalic child. Brain1949;72:373-381

2. Quinlan RA, Brenner M, Goldman JE, Messing A. GFAP and its role in Alexander disease. Exp Cell Res 2007;313:2077-2087.

3. Yoshida T, Nakagawa M. Clinical aspects and pathology of Alexander disease, and morphological and functional alteration of astrocytes induced by GFAP mutation. Neuropathology 2011; Nov 28:14401789. [Epub ahead of print]

4. van der Knaap MS, Naidu S, Breiter SN, et al. Alexander disease: Diagnosis with MR imaging. Am J Neuroradiol 2001;22:541-552

5. Ball WS, Egelhoff JC, Jones BV, et al. Metabolic, Congenital, Neurodegenerative and Toxic Disorders. In:Clinical Magnetic Resonance Imaging, 3rd ed. Edelman RR, Hesselink JR, eds. Philadelphia, USA: Saunders, 2006:1656-1704.

6. Klein EA, Anzil AP. Prominent white matter cavitation in an infant with Alexander's disease. Clin Neuropathol 1994;13:31-38. 